\title{
Using Social Networks in Knowledge Management System*
}

\author{
Mikhail Oseledchik \\ Department of Philosophy and Social Sciences \\ High School of Printing and Media Industry \\ Moscow Polytechnic University \\ Moscow, Russia \\ E-mail: balu13@yandex.ru
}

\author{
Marina Ivleva \\ Faculty of Humanities and Social Sciences \\ Peoples' Friendship University of Russia \\ 6 Miklukho-Maklaya Street \\ Moscow, Russia \\ E-mail: marinanonna@yandex.ru
}

\author{
Vitaly Ivlev \\ National Research University \\ Moscow State Technical University named after N.E. \\ Baumann \\ Moscow, Russia \\ E-mail: vitalijivlev@yandex.ru
}

\begin{abstract}
The article analyzes the positive and negative aspects of using social networks in the knowledge management system, formal and informal components of knowledge management by advanced organizations, non-standard ways of incrementing and storing knowledge. The use of social networks in knowledge management is a powerful positive tool for disseminating and increasing knowledge in an organization. The article lists the twelve main positive features of social networking. The description of experiments that prove the need for social interaction to preserve knowledge is given. The author focuses on such feature of social networks as its effectiveness in the transmission of both explicit and implicit knowledge.
\end{abstract}

Keywords-social networks; knowledge management; knowledge; knowledge increment; knowledge storage

\section{INTRODUCTION}

In recent decades, in modern management has deeply rooted a paradigm, according to which the modern economy is primarily a knowledge economy. Knowledge is considered as one of the most important conditions for the competitiveness of a social institution. The one who knows more and, accordingly, can do more, achieves greater economically significant results. Thus, knowledge management as a system for preserving, dissemination and reconfiguration of existing knowledge and for producing new knowledge gets a fundamental importance. The presence in the knowledge system of the social institution of explicit and implicit components creates additional difficulties and the strategic importance of the development

*The study was carried out with the financial support of the Russian Foundation for Basic Research in the framework of the research project ["Ecological paradigm in the public consciousness: formation and development"], project No. 18-013-00488. of the knowledge management system.

Explicit knowledge is fundamentally codified knowledge that is stored in the form of documents, instructions, regulations, drawings and other media that any employee of any department of a social institution can use, unless this knowledge is a commercial secret and access to it is, for obvious reasons, strictly limited for most members of the organization.

Implicit knowledge is personalized knowledge that is the property of a person, it is strictly individualized knowledge, which is not always, even in principle, possible to codify and further circulate between the users interested in it. One of the fundamental tasks of knowledge management is to identify and to single out this individualized knowledge and to preserve it in the form of relevant documents, which in turn can be freely used by other members of the institute, if necessary.

And here it is necessary to pay attention to the motivation of employees: not all are ready to share their knowledge, because this inevitably leads to the loss of their personal competitive advantage over other members of this social institution and reduces the opportunities for obtaining another prestigious and highly paid workplace in the labor market. Therefore, one more super task of knowledge management is to create the system of positive motivation of employees for voluntary distribution, the so-called socialization of individual knowledge, i.e. the system of moral and material encouragement of more experienced knowledge carriers, if they are willing to share their knowledge, and to develop the organizational security system for dissemination of their knowledge, when the loss of their individual competitive advantage over other employees does not entail fear of dismissal or change to less 
significant positions in the internal hierarchy of this social institution.

\section{THE ROLE OF SOCIAL NETWORKING IN KNOWLEDGE MANAGEMENT}

All these diverse tasks can be solved by the knowledge management system, by using as its tool a variety of communication channels: personal communication, intranet of the social institution, corporate training and consulting systems, etc. Recently, it has become very interesting to observe how, in addition to the official communication channels of the social institution, the concerned employees use unofficial channels. And a fundamental role among unofficial channels is played by social networks, without which in our time it is very difficult to imagine the life of a modern person.

The avalanche-like spread of the Internet as the basic communication environment naturally generated the need for gadgets, which give an opportunity to quickly and comfortably enter its space, while the diversity of electronic devices [smartphones, tablets, etc.] in turn pushes forward the emergence of more and more Internet technologies and another ideology of communication. One of the results of this dialectical process was the development of social networks. The catalogs available on the Internet offer lists of more than four hundred and fifty networks, while it is clear that in reality there are much more of them. What is a social network? Wikipedia gives the following definition: "A social network is a platform, an online service or a website designed to build, reflect and organize social relationships on the Internet" [1]. Another definition is: "In recent years, the term" social network "refers to Internet services which allow users to transfer to the web their social connections, but the very concept of social network was proposed long before the creation of personal computers. A scientific definition says that a social network is a structure [mathematically it is a social graph], which consists of a group of nodes represented by people or organizations, as well as links between nodes. Relationships can express one or another relationship: for example, kinship, acquaintance or teamwork" [2].

In the functioning of the knowledge management system of a social institution, social networks also began to play a significant role. A lot of advanced corporate structures began with readiness to create corporate social networks. But often their users are much more active and more effective in communicating in the world's social networks, such as VKontakte, Facebook, Instagram, etc., as well as in specialized social networks that unite professionals and scientists.

Why is this happening? What does communication in social networks give, unlike the capabilities of the official communication system of corporate knowledge management?

\section{ADVANTAGES OF SOCIAL NETWORKS}

We would like to highlight a few fundamental advantages of social networks:
- Mobility and availability - the ability to easily and comfortably enter the social network from any device connected to the Internet;

- Anonymity of participation in the process of communication - the possibility not to give your real name, but to use a pseudonym, which gives you greater freedom in published statements, questions and behavior; when a person is not afraid of being recognized and of the chance of negative consequences of this, it is much easier for him to behave in the way which is not standard for him in corporate etiquette and thinking;

- Linguistic simplicity and informality of communication - social media is increasingly using everyday language, slang, even colloquial expression for expressing sometimes quite complex information and for giving their points of view even in narrow professional issues, texts in social network are in most cases more clear and intuitively are more transparent; here, figurative comparisons, jokes, ironic remarks, sarcasm are more often used; moreover, in the social network, narrativity - the presentation of a certain point of view in the form of a story, some kind of instructive narration - is welcomed; it is extremely important to have a dialogical character of communication, the possibility of informal friendly conversation without looking at colleagues and superiors;

- Lack of hierarchy in communication - the ability to directly communicate with any interlocutor yourself, i.e. communication with any user of the network is not limited to regulatory procedures and does not depend on the will and decision of other people who can, within the frames of everyday life of the social institution, allow or make the communication possible, or they can put obstacles on the way of such communication; there are practically no such intermediaries in the social network; communication becomes alive and direct;

- Informativeness and saturation - within the social network, the participant of communication is practically guaranteed to find the necessary answers to the question which is of interest to him or he receives some ideas about where to find such an answer; It is understandable that periodically you can find very questionable information or even frankly false information, but it's not strange, such information also has a kind of heuristic importance, since its use, not without possible problems, of course, can give a new insight into the essence of the problem, the trial and error method until now has not lost its effectiveness in obtaining new knowledge;

- Pluralism of opinions - there are diametrically opposed opinions in the network, a whole range of them depends only on the position of their creators, and not on the point of view traditionally adopted within a particular social institution; this makes it 
possible to get the idea of a rather unusual solution to some problem, a solution which can more than drastically differ from the traditional standards of the solution taken within the social institution;

- Criticality and controversy - a feature which logically follows from the previous point; any stated point of view can immediately be criticized and challenged regardless of the real social status of its author; as we known, constructive criticism is the most important means of moving forward in the search for truth, thanks to constructive criticism it is much easier to see weaknesses in one's own point of view and to find heuristic solutions for the current problem situation;

- Temporal continuity of communication - at whatever time of day and night a person would go online, there are always interlocutors with whom you can discuss issues and topics of your interest; here there is no need to wait for the beginning of the working day and the appearance of the desired interlocutor;

- Unselfishness of communication - in the social network in the majority of cases there is a free exchange of information, mutual enrichment of each other with knowledge does not lead a participant in such communication to lose their competitive advantage within the social institution of which the communicant is a member;

- Freedom of communication - access to the network is in no way regulated by any corporate requirements and depends only on the will and desire of a particular individual; he goes to the network only and if he is really personally interested in something and really wants to communicate;

- High probability to find unusual interlocutors - the network can often surprise you by the fact that you can find unknown to you people: professionals, who you did not know and never heard of; unusual nonstandard scholars; opponents; like-minded people, etc.; in the network there are a lot of people, among which, due to the law of large numbers and informal communication, you can find unusual people and unusual points of view;

- Self-organization - a social network is always a selforganizing system in which users have a high degree of freedom of personalization and customization, which is often impossible within the framework of official regulations.

These are the features of social networks that are not essentially exclusive, but in their dynamic combination give a positive integral effect, and force people to actively use them, including the need to implement the tasks and functions of knowledge management. This is reason that the often makes advanced social institutions create corporate social networks. The results are excellent.

Here, we deliberately do not discuss the negative aspects associated with the use of social networks in the knowledge management system. They are described in detail in a number of sources [3] [4]. From the author's point of view, the negative aspects here are much inferior to positive ones and do not have any significant impact on achieving the final result.

The experiment, carried out by Canadian and American scientists, proved the importance of social networks and social interaction for preserving knowledge. The experiment was based on the fact that the volunteers were divided into two groups: in one, each student could learn from only one teacher and transfer knowledge to only one student. In the second group, the student could learn from five teachers being the member of a group. The results showed that groups of singles retain knowledge at the level of the first generation or lose part of it. The knowledge of the second group was much better and with each new generation of students all students improved [4].

Another study "The role of new technologies in accelerating cooperation and knowledge transfer" was conducted in 2006-2007 among several advanced social institutions, first of all, they were Accenture [a company that provides global management, consulting and outsourcing services for 15 industries in different countries], HewlettPackard, Royal Dutch Shell [an international group of energy and petrochemical companies], Siemens [one of the leading companies in the field of electronics and electrical engineering], and the US State Department [5]. It turned out that the employees of these organizations with great pleasure and enthusiasm use social networks for writing documents, for fixing knowledge, for managing projects, and for other joint purposes. "These organizations, called partners with best practices, were selected for their innovative activities in one or more of the following areas of research:

- Harmonization of the information management strategy [IM], architecture and components to support the transfer of knowledge;

- Integration of information management with initiatives of knowledge management [KM];

- Addressing organizational and cultural issues;

- Evaluation of current and future trends in technology" [5].

And here we have to give another quotation:

"Throughout the study, the research team identified nine topics. Approaches used in organizations with best practices in many ways provide the understanding of how they successfully adapt the approaches of social computerization" [5].

The list of these topics looks as follows:

Wikis, blogs and social networks create the greatest effect. There is a democratization of content between authoring content and group knowledge.

- Collaboration underlies knowledge management, however, with the expansion of digital communication capabilities, the definitions of community and cooperation are blurred. 
- Increasing attention is paid to communication between people and less emphasis is placed on the collection and management of content. The ability to connect users often complements the need for content collection.

- Organizations, which apply best practices, provide users with the freedom to use collaboration technology, and to experiment with various tools and approaches. The tools are user-oriented and largely depend on local content.

- Using Enterprise 2.0 applications does not require changes in policy or security updates. In addition, there is the readiness to reduce the volume of publications of authorized content, and to make it accessible to the entire organization [5]. Organizations with best practices have not experienced significant problems with the abuse of tools, or the dissemination of inappropriate or confidential information

- Relationships between KM and IT functions are very close, this partnership is driven by a common desire to understand the users and needs of the business and to provide the tools that correspond to them.

- IT and Enterprise 2.0 applications currently run in parallel mode. Integration will create problems in terms of enterprise IT architecture, content management, research of efficiency, and the cost of launching several non-standard applications.

- Change management and deployment are surprisingly compatible in all organizations, which apply best practices.

- In order to demonstrate the importance of implementing Enterprise 2.0, organizations with best practices rely on the effectiveness of indicators, success stories and lessons learned.

These organizations specifically create communities on topics for sharing knowledge and actively use in this process blogs and wikis for discussion.

All this is organized on special servers and platforms, which allow company employees to create their own spaces both inside and outside the company. Companies at the same time are actively creating their own social networks, for example, Royal Dutch Shell has created its Wiki Shell network, taking as a basis Wikipedia. This network has quickly become the working environment for the exchange of knowledge between communities and disciplines. Thus, blogging is becoming a part of corporate culture (blogs replace laboratory journals for researchers, since they could be submitted to patent offices as an acceptable record format)

Another interesting innovation: "All approaches to knowledge management used by Shell are supported by the behavioral model Ask-Learn-Share. The philosophy behind this model is that before starting any activity, the employee should first search for existing information, and only after that ask colleagues and experts for help and advice" [5].

Siemens integrated corporate blogosphere into its global Internet quarters, any employee has access to it. The company uses wikis to create dictionaries and glossaries, which allows employees to facilitate work with different types of documents.

\section{CONCLUSION}

New technologies really democratize access to knowledge, its dissemination and increment. Thus, an effective organization for developing its own knowledge management system actively uses social networking, focusing on its advantages, worldview and behavioral philosophy.

\section{REFERENCES}

[1] Social network [Electronic resource]. - Access mode: https://ru.wikipedia.org/wiki/\%D0\%A1\%D0\%BE\%D1\%86\%D0\%B8 $\% \mathrm{D} 0 \% \mathrm{~B} 0 \% \mathrm{D} 0 \% \mathrm{BB} \% \mathrm{D} 1 \% 8 \mathrm{C} \% \mathrm{D} 0 \% \mathrm{BD} \% \mathrm{D} 0 \% \mathrm{~B} 0 \% \mathrm{D} 1 \% 8 \mathrm{~F} \% \mathrm{D} 1 \%$ 81\%D0\%B5\%D1\%82\%D1\%8C. - 23.02.2018

[2] A. Batogov, Thanks to social networks, mankind grows wiser over time [Electronic resource]. - Access mode: http://hi-news.ru/researchdevelopment/blagodarya-socialnym-setyam-chelovechestvo-sovremenem-umneet.html - 21.12.2015.

[3] N. Perov, Harm of social networks: influence on the psyche [Electronic resource] / N. Perov. - Access mode: http://nperov.ru/soznanie/vred-socialnyx-setej-vliyanie-na-psixiku 11.09.2016.

[4] Understanding of practical intelligence [Electronic resource]. Access mode: https://murzim.ru/psihologija/prakticheskijintellekt/10933-ponimanie-prakticheskogo-intellekta.html05.12.2016.

[5] A. Garin, Internet Marketing: Knowledge Management in Advanced Organizations [Electronic resource] /A. Garin.- Access mode: http://www.klubok.net/index.php?name=News\&file=article \&sid=254 9\&theme - 01.01.2016 